Revista Destaques Acadêmicos, Lajeado, v. 10, n. 2, 2018. ISSN 2176-3070

DOI: http://dx.doi.org/10.22410/issn.2176-3070.v10i2a2018.1815

http://www.univates.br/revistas

\title{
A JUDICIALIZAÇÃO DAS POLÍTICAS PÚBLICAS NO BRASIL SOB A PERSPECTIVA DA SEPARAÇÃO DE PODERES, RESERVA DO POSSÍVEL E DO MÍNIMO EXISTENCIAL
}

\author{
Pablo Florentino Fróes Couto ${ }^{1}$
}

\begin{abstract}
Resumo: A revisão de literatura aborda as controvérsias que orbitam a judicialização da política. A atividade judicial vem avançando consideravelmente sobre a política e as relações sociais. Diante disso, o juiz se tornou mais próximo da sociedade. Esse protagonismo judicial é condição indispensável para a efetiva proteção dos direitos sociais, contribuindo, portanto, para a estabilidade da democracia. Contudo, a atuação do judiciário demanda dispêndio dos recursos públicos. A doutrina da reserva do possível, em contrapartida, entra nesse cenário como garantidor dos direitos fundamentais da coletividade.
\end{abstract}

Palavras-chave: Judicialização da Política. Direitos Sociais. Doutrina da Reserva do Possível.

\section{INTRODUÇÃO}

Os direitos sociais são fundamentais. A promoção ou proteção desses direitos exige ações ou omissões por parte do Estado. Da obrigação de não fazer do Estado, se exige o respeito aos direitos fundamentais. Do outro lado, da obrigação de fazer se exige a proteção, a garantia e a promoção de direitos pelos entes estatais (HÄBERLE, 1980; SARMENTO,2004; BARCELLOS, 2006). Exemplificando, o Estado a priori não pode em tese interferir para violar a liberdade de ir e vir dos cidadãos, havendo aqui o dever de omissão. $O$ indivíduo é em regra livre. Por outro lado, o Estado deve prestar um serviço de polícia e vigilância, com intuito de garantir que a integridade física e patrimonial do cidadão não seja violada por outros indivíduos. Tanto a segurança como

1 Mestrando em Direito Constitucional pelo Instituto Brasiliense de Direito Público (IDPDF). Pós-graduado em Direito Processual pela Universidade Estadual de Montes Claros (UNIMONTES). Pós-graduado em Direito e Processo do Trabalho pela Universidade Anhanguera-Uniderp. Professor de Direito do Instituto Federal do Norte de Minas Gerais (IFNMG) e advogado. pablo.couto@ifnmg.edu.br 
a fruição de outros serviços estatais (educação, saúde e assistência social) dependem de gastos públicos.

Nesse sentido, tese plausível é aquela que alega que todos os direitos têm custos. Isto é, segurança pública, serviços judiciais, serviços cartorários, atividades legiferantes do parlamentar, atividades de gestão administrativa, cobrança de impostos, forças armadas, bem como direitos sociais: programas de renda mínima, de habitação popular, a assistência social, escolas e creches públicas, todos demandam o dispêndio de recursos públicos (GALDINO, 2005; BARCELLOS, 2006; LOPES, 2008).

O cerne do problema é saber se são plenamente justiciáveis a questão do quanto, com que finalidade, em quê e como gastar o dinheiro advindo dos tributos. Será que o Poder Judiciário possui uma função política e por causa disso pode controlar as políticas públicas ou o gasto público? Sendo os recursos públicos limitados, há direitos que estão num patamar superior aos orçamentos públicos? Busca-se no presente artigo traçar parâmetros jurídicos para responder as indagações.

\section{A JUDICIALIZAÇÃO DAS POLÍTICAS PÚBLICAS NO BRASIL}

Os direitos sociais previstos na Constituição se sujeitam à uma prestação positiva estatal e possuem eficácia imediata (GRINOVER, 2014). Essa prestação positiva em tela depende da organização do Estado, que por sua vez fixa e implementa as políticas públicas por meio da função legislativa (leis) e da função administrativa (GRINOVER,2014).

As políticas públicas, destarte, são instrumentos que servem para efetivar os direitos sociais, como a saúde, educação, previdência e moradia (BUCCI, 1996; FREIRE,2005). Nesse sentido:

É fácil perceber que apenas por meio de políticas públicas o Estado poderá, de forma sistemática e abrangente, realizar os fins previstos na Constituição (e muitas vezes detalhados pelo legislador), sobretudo no que diz respeito aos direitos fundamentais que dependam de ações para a sua promoção. (BARCELLOS, 2005, p.90).

Contudo, o que se entende por políticas públicas? A políticas públicas estão vinculadas historicamente a uma tradição intervencionista do Estado. Logo, os particulares estariam excluídos da condição de agentes ativos, pois estes não praticam políticas públicas, mas sim ações privadas de interesse público ( BERCOVICI, 2006; FONTE,2013;). As políticas públicas seriam conjuntos de programas (macrodiretrizes estratégicas) que designam ações estatais, sob sequência processualizada e planejada, com a finalidade de resolver os problemas públicos (COMPARATO,1998; GRAU,2001; BUCCI, 2002; MASSA-ARZABE, 2006). 
Todavia, frequentemente os poderes políticos, especialmente por parte da Administração, se quedam inertes ou executam as políticas de modo inadequado, destoando dos direitos elencados no art. $6^{\circ}$ da Carta Magna ou dos objetivos fundamentais da República Federativa do Brasil, conforme o art. $3^{\circ}$ da Constituição Federal (GRINOVER, 2014). É neste contexto que surge a necessidade de se buscar a função jurisdicional, provocada sempre através da ação, cujo escopo é exercer o controle de constitucionalidade da política pública, resultando sobre esta uma intervenção, seja corrigindo-a ou implementando-a (GRINOVER, 2014).

Durante a década de 90, as medidas neoliberais adotadas pelo governo resultaram no crescimento do desemprego e na degradação da proteção social (SIERRA, 2011). Isso possibilitou o aumento desmensurado da judicialização das políticas públicas movida pela população. O que os cidadãos pretendiam? Eles buscavam o Poder Judiciário como o último reduto da proteção social, que assegurasse a efetivação dos direitos de cidadania, já que estavam diante da escassez de políticas públicas no contexto neoliberal (VIANNA, BURGO, SALLES, 2007; SIERRA, 2011).

A Constituição brasileira atendeu essa demanda ao consagrar os direitos sociais ao longo do seu texto, especialmente no capítulo II (SIERRA, 2011). Como resultado, a Lei Maior prevê meios processuais de provocar o Poder Judiciário: o controle de constitucionalidade por omissão (art. $103 \S 2^{\circ}$ ), o mandado de segurança (art. $5^{\circ}$, inciso LXIX), mandado de injunção (art. $5^{\circ}$, LXXI), a ação por descumprimento de preceito fundamental (art. $102 \S 1^{\circ}$ ) e o controle abstrato de normas (art. 103, I ao IX).

A possibilidade de acionar o Poder Judiciário provoca a politização da justiça (SIERRA, 2011). A Constituição da República elenca uma série de princípios e mecanismos processuais que fica sob a responsabilidade do cidadão de pleiteá-la perante os tribunais, o que seria uma forma de pressão e mobilização política sobre o Poder Judiciário (CITTADINO, 2004). Nessa esteira:

A invasão do direito sobre o social avança na regulação dos setores mais vulneráveis, em um claro processo de substituição do Estado e dos recursos institucionais classicamente republicanos pelo judiciário, visando a dar cobertura à criança e ao adolescente, ao idoso e aos portadores de deficiência física. O juiz torna-se protagonista direto da questão social. Sem política, sem partidos ou uma vida social organizada, o cidadão volta-se para ele, mobilizando o arsenal de recursos criado pelo legislador a fim de lhe proporcionar vias alternativas para a defesa e eventuais conquistas de direito. (VIANNA, BURGOS, SALLES, 2007, p.41).

Durante as últimas décadas, a atividade judicial avançou consideravelmente sobre a política e relações sociais (SIERRA, 2011). Com 
efeito, o juiz se tornou mais próximo da sociedade, num trabalho de valorização da cidadania (SIERRA, 2011). Por outro lado, a judicialização da política vem causando controvérsias doutrinárias, sobretudo em torno da separação de poderes e da reserva do possível, o que será abordado a seguir.

\section{CONTROVÉRSIAS DA JUDICIALIZAÇÃO DA POLÍTICA PÚBLICA: SEPARAÇÃO DE PODERES E RESERVA DO POSSÍVEL}

Montesquieu (2000) condicionou a liberdade à separação de três funções: judicial, legislativa e executiva. Assim, foi criada a teoria da separação dos poderes que se opunha à reunião dos poderes, esta que dava margem ao surgimento de leis tirânicas.

Naquela época, como lembra Dallari (2007), a teoria em apreço foi consagrada sob o paradigma do liberalismo, onde se objetivava o enfraquecimento do Estado em detrimento do fortalecimento das liberdades individuais. $\mathrm{O}$ modelo constitucional vigente, segundo o mesmo autor, se preocupava em proteger o indivíduo diante das ingerências do Estado, este que tinha por obrigação de se abster para que o cidadão possa usufruir da liberdade (liberdade negativa). Na teoria clássica o Juiz era considerado apenas "a boca da lei", pois se sujeitava completamente ao império da lei emanada do Poder Legislativo (MONTESQUIEU,2000).

Entretanto, os ventos dos mares mudaram de rumo. As massas reivindicavam direitos durante a revolução industrial. A concepção de Estado e suas finalidades acabaram se modificando. Como resultado, houve a transição do Estado Liberal para o Social, onde o Estado passa a existir para atender o bem comum, satisfazer os direitos fundamentais e garantir a igualdade material (GRINOVER, 2014).

A Constituição Federal de 1988 acrescenta mais uma transição: o Estado Social se transforma em Estado Democrático de Direito. O Estado assume mais um novo papel. Ele passa a ser o agente transformador da realidade social, possuindo metas, programas, finalidades na Constituição, além de estabelecer funções específicas aos Poderes Públicos. O poder do Estado, embora uno, é exercido por suas três formas de expressão (legislativo, executivo e judiciário) e todas visam a consecução da política estatal preestabelecida na Lei Maior (CANELA JUNIOR,2009; GRINOVER, 2014).

O Poder Judiciário agora se encontra vinculado à política estatal, alinhado com os escopos do próprio Estado, não é mais um poder neutro como era no paradigma liberal ("boca da lei"), e, precipuamente, o seu papel é investigar o fundamento de todos os atos estatais a partir dos objetivos fundamentais previstos no art. $3^{\circ}$ da Constituição (JUNIOR, 1994; CANELA JUNIOR,2009).

Não obstante, existe o questionamento que indaga se é democrático um juiz ou tribunal, que não tem sua legitimação através do voto popular, tomar decisões morais fundamentais no lugar de toda a sociedade ou 
invalidar as decisões políticas do legislador democraticamente eleito (BICKEL,1986; SCHÄFER,2001). De acordo com Bickel (1986), a dificuldade quanto à legitimidade reside no fato de o poder jurisdicional ser uma força contramajoritária no sistema (conter-majoritarian difficult). Para a autora Karine da Silva Cordeiro, é democrático a atuação do Poder Judiciário sobre as decisões políticas do legislador segundo a concepção substancial da democracia:

(...) Porém, uma vez adotada a concepção substancial de democracia, a resposta é necessariamente positiva. A legitimidade democrática dos juízes advém justamente desta aparente contradição: embora a função dos juízes constitucionais seja política, eles não pertencem à política. $\mathrm{O}$ propósito não é aumentar o poder dos juízes, desequilibrando a balança em prol do judiciário, e sim, aumentar a proteção da democracia e dos direitos fundamentais (CORDEIRO, 2011, p. 147).

No Brasil, a última instância que protege e concretiza os direitos fundamentais é o Poder Judiciário (CORDEIRO, 2011). O princípio da inafastabilidade do Poder Judiciário foi previsto e ampliado pela Constituição de 1988, visto que o referido princípio abrange a lesão a direito, ameaça e a proteção dos direitos coletivos (CORDEIRO, 2011). Além disso, a Constituição brasileira não possui um sistema onde todas as competências são exaustivamente tipificadas, muito pelo contrário, a Constituição, além de enumerar as competências dos tribunais, adotou a técnica de atribuição de competências de modo residual a certo órgão jurisdicional (SCHÄFER, 2001; CORDEIRO, 2011). Assim, no Brasil não existe espaço para se sustentar que há vazios constitucionais no âmbito das competências, seja qual for a matéria a ser debatida, porque os juízes brasileiros detêm competência para conhecê-la (CORDEIRO, 2011).

A experiência histórica com diversos regimes totalitários tem revelado que não é prudente deixar os direitos fundamentais exclusivamente nas mãos daqueles que foram eleitos pelo voto da maioria ou até mesmo com gigantescas vitórias eleitorais (CORDEIRO 2011; GRIMM, 2011). Na realidade política, social e cultural do Brasil, o processo político majoritário vem se distanciando dos anseios da sociedade, as virtudes republicanas têm se tornado incomuns e a desigualdade social é um fenômeno gritante (CORDEIRO, 2011). Por consequência, o protagonismo judicial é condição indispensável para a efetiva proteção dos direitos sociais, contribuindo para a estabilidade da democracia (CORDEIRO, 2011). Logo, a opção do Constituinte de 1988 foi a mais acertada.

Por outro lado, essa exigibilidade dos direitos sociais atendida pela magistratura gera a obrigação do Estado de realizar gastos públicos, porém nem sempre existem recursos disponíveis para oferecer todos os direitos previstos na Constituição para todas as pessoas (WANG,2008). Muitas vezes, a Administração não dispõe ou não pode dispor de recursos suficientes para 
satisfazer os anseios das decisões judiciais sem prejudicar a tutela de direitos de outros cidadãos (WANG,2008).

Diante de tal constatação, parcela da doutrina sustenta que há um limite fático no momento de se exigir os direitos sociais, visto que tais direitos são dependentes da idoneidade econômica do Estado, ou seja, da limitada cobertura financeira estatal, o que jamais pode ser simplesmente ignorado pelas decisões dos magistrados (CANOTILHO, 1988; AMARAL, 2001; QUEIROZ, 2005; ALEXY, 2007). O limite fático em questão é chamado em alguns trabalhos e jurisprudências como reserva do possível (WANG, 2008).

A reserva do possível é tudo aquilo que o cidadão pode razoavelmente exigir do Estado, especificamente da sociedade (ALEXY, 2007). Na verdade, não se postula a ineficácia dos direitos que requeiram a prestação positiva estatal, mas sim se atenta pela necessidade de ponderar as prestações estatais em face de outros direitos (ALEXY,2007). Em suma, os direitos sociais não são absolutos e nem aplicáveis em todos os casos definitivamente, pois eles podem sofrer delimitações por causa da colisão com outros direitos e interesses no caso concreto (ALEXY, 2007).

O Poder Judiciário deve zelar e aplicar os direitos sociais com cautela e muita responsabilidade, uma vez que os juízes devem ter ciência do problema da escassez de recursos. As suas sentenças ou acórdãos não podem ignorar as consequências econômicas e distributivas em virtude da adjudicação de direitos (WANG, 2008).

Nessa esteira, cumpre frisar que em se tratando de necessidades financeiras não se pode, imprudentemente, debitar ao Estado uma conta que não se fecha, proibindo qualquer discussão sobre isso (LOPES, 2008). Além de tudo, essas contas nem sempre encontram correspondência com os propósitos que a Constituição assimila como Justiça Social, o que faz alimentar a ideia de que é impossível cumprir todas as promessas aparentemente utópicas da Constituição de 1988 (GALDINO,2005; LOPES, 2008). Ledo engano imaginar que o Estado pode dar a mesma coisa para todos. Nas palavras de José Reinaldo da Silva Lopes:

Engana-se quem acha que o Judiciário deve dar a um cidadão aquilo que este não conseguiu da Administração porque ela não teria como dar a mesma coisa a todos. Se o Judiciário concedesse a um em particular, estaria certamente violando o direito de todos os outros pois atenderia com recursos públicos apenas os que conseguissem chegar a ele. Com o tempo, transferir-se-ia para os tribunais a fila de atendimento. E ao fim do dia ele seria, da mesma forma que a Administração, obrigado a fechar as portas. Isto porque essa maneira ingênua de pensar levaria aos tribunais a multidão dos famintos e necessitados que seriam servidos por vez de chegada, mas sem um critério de distribuição universal e simultânea. O Judiciário não estaria aplicando a regra, não estaria tratando a todos igualmente, 
não estaria valorizando igualmente a vida de cada cidadão, mas apostando (de forma lotérica, portanto) que alguns não chegariam à justiça e que esses não lhe importam, que esses não devem ser levados em consideração. (LOPES, 2010, p. 171-172).

Nesse sentido, as decisões que pleiteiam direitos sociais ao indivíduo “(..) tendem a beneficiar alguns privilegiados e podem gerar dificuldades orçamentárias em detrimento de todos os demais indivíduos que não podem ir a juízo reclamar igual prestação jurisdicional" (LUPION, 2008, p. 323).

Em balanço, considerando que é impossível proteger todos os direitos por causa da escassez de recursos, portanto em nossa opinião o magistrado deveria analisar cuidadosamente cada política pública judicializada. O juiz deve escutar cada gestor, cada economista ou especialista, desenvolver ações dialógicas com todos os setores envolvidos, traçar conjuntamente estratégias futuras com os mesmos, ponderando a urgência do caso, bem como verificando se a situação concreta se trata de uma necessidade coletiva ou de uma necessidade puramente individual. Em arremate, observa Ana Paula Barcellos (2006) que os recursos públicos são limitados e é essencial fazer escolhas; logo, em certa medida, a Constituição vincula as escolhas no quesito políticas públicas, como também o gasto dos recursos públicos.

Por fim, há outra questão perturbadora. Segundo Ana Paula Barcellos (2006), tornou-se corrente afirmar que o gozo minimamente adequado dos direitos fundamentais é uma condição crucial para o funcionamento regular da democracia. Sem o respeito a esse conjunto mínimo de direitos fundamentais (condições básicas de existência digna), os indivíduos não terão condições de exercer suas liberdades, de participar conscientemente do processo político, do processo democrático e nem do diálogo no espaço público (MAIA, 2000; BINENBOJM, 2001; NASCIMENTO, 2002; SOUZA NETO, 2003; HABERMAS, 2003). Ante o exposto, é pertinente indagar: a reserva do possível é aplicável ao gozo minimamente adequado dos direitos fundamentais (mínimo existencial)? O que é o mínimo existencial? O próximo item tratará dessas questões.

\section{DO MÍNIMO EXISTENCIAL SOB O LIMITE DA RESERVA DO POSSÍVEL}

Convém observar que não entraremos na discussão filosófica sobre o que seria o mínimo existencial, mas traçaremos alguns parâmetros jurídicos com a finalidade de provocar o debate sem, no entanto, esgotar as polêmicas de caráter teórico.

Nesse desiderato, o mínimo existencial não é um objeto imutável, perene e absoluto; e que a comunidade constituinte política elegeu o Estado Democrático e Social de Direito fundamentada na dignidade da pessoa humana como valor máximo da ordem jurídica, esta que garante a todos o mínimo existencial (CORDEIRO, 2011). Por conseguinte, admitindo a responsabilidade 
constitucional do Estado em garantir os riscos da existência, cabe delimitar a extensão e as fronteiras do mínimo existencial, o que não é de longe tarefa fácil, especialmente se levarmos em conta uma sociedade pluralista (TORRES, 2009; CORDEIRO 2011).

O mínimo existencial é composto por prestações materiais destinadas a prover a vida do indivíduo com dignidade (CORDEIRO,2011). Esse mínimo é irredutível, insuscetível de ponderação, porque constitui o conteúdo essencial dos direitos fundamentais (TORRES, 2009).

Entretanto, convém esclarecer que nem todos os direitos fundamentais sociais têm todo o conteúdo abarcado pela dignidade da pessoa humana, embora todos eles tenham um núcleo essencial (FIGUEIREDO, 2007; SARLET, 2018). Deste modo, a ideia central orbita na possibilidade de se identificar dentro de cada direito fundamental um conjunto de bens que seja absolutamente removido do processo de ponderação (MACHADO,2001; SARLET,2008).

Contudo, essa resposta não é simples. A doutrina, conforme a observação de Canotilho (2003), Pereira (2006) e Cordeiro (2011) se encontra dividida entre as teorias absoluta, relativa, objetiva, subjetiva e mista. A teoria absoluta defende que a norma constitucional fundamental preestabelece em seu corpo duas partes, sendo uma de conteúdo essencial (não pode ser ponderado) e uma de conteúdo não essencial ou acessório (pode ser ponderado). A teoria relativa diz que o núcleo essencial é estabelecido em cada caso concreto por meio do processo de ponderação. A teoria objetiva afirma que o texto constitucional está protegido. Por outro lado, a teoria subjetiva afirma que a proteção é sobre o direito subjetivo do indivíduo. A teoria mista mescla as quatro teorias. Em suma, a última teoria diz que o conteúdo essencial é em parte estabelecido pela própria norma a priori, como também é estabelecido no caso concreto a posteriori, pela via da ponderação. Além disso, tanto o texto constitucional, como também o direito subjetivo do indivíduo estão protegidos e são complementares.

Autores como Arango (2005) e Sarlet (2018) entendem que o mínimo existencial está além da sobrevivência física do indivíduo. É necessário que o Estado propicie condições para o pleno desenvolvimento da personalidade, ou seja, o Estado deve oferecer, por meio de prestações materiais, um standart de vida que corresponda às perspectivas do princípio da dignidade da pessoa humana (BITENCOURT NETO, 2010; CORDEIRO, 2011).

KRELL (2002), BARCELLOS (2003), LEIVAS (2006), SARLET (2008), TORRES (2009) e BITTENCOURT NETO (2010), todos eles arrolam um conjunto de direitos que compõe o círculo do mínimo existencial. São eles: necessidade de vida física, alimentação, vestuário, assistência à saúde, educação, necessidade espiritual-cultural, socialidade, moradia, assistência e previdência social, água, saneamento básico, proteção do trabalhador, transporte, energia elétrica, renda mínima, assistência jurídica e acesso à justiça, 
Sarlet (2008) e Caliendo (2013) entendem que a reserva do possível não é óbice para o fornecimento e a preservação do mínimo existencial necessário à dignidade da pessoa humana. A mesma tese é defendida por TORRES (1995), BARCELLOS (2003) e COSTA (2005). Do lado oposto, há os defensores da reserva do possível como entrave da realização de direitos fundamentais em razão da escassez de recursos. Nesse sentido, AMARAL (2001), MORAIS (2004) e PEGORARO (2005).

Pertinente decisium sobre a controvérsia, transcrevemos o trecho da seguinte ementa:

Não deixo de conferir, no entanto, assentadas tais premissas, significativo relevo ao tema pertinente à "reserva do possível" (STEPHEN HOLMES/CASS R. SUNSTEIN, "The Cost of Rights", 1999, Norton, New York; ANA PAULA DE BARCELLOS, "A Eficácia Jurídica dos Princípios Constitucionais”, p. 245/246, 2002, Renovar), notadamente em sede de efetivação e implementação (sempre onerosas) dos direitos de segunda geração (direitos econômicos, sociais e culturais), cujo adimplemento, pelo Poder Público, impõe e exige, deste, prestações estatais positivas concretizadoras de tais prerrogativas individuais e/ou coletivas. Não se ignora que a realização dos direitos econômicos, sociais e culturais - além de caracterizar-se pela gradualidade de seu processo de concretização - depende, em grande medida, de um inescapável vínculo financeiro subordinado às possibilidades orçamentárias do Estado, de tal modo que, comprovada, objetivamente, a alegação de incapacidade econômico-financeira da pessoa estatal, desta não se poderá razoavelmente exigir, então, considerada a limitação material referida, a imediata efetivação do comando fundado no texto da Carta Política. Não se mostrará lícito, contudo, ao Poder Público, em tal hipótese, criar obstáculo artificial que revele - a partir de indevida manipulação de sua atividade financeira e/ ou político-administrativa - o ilegítimo, arbitrário e censurável propósito de fraudar, de frustrar e de inviabilizar o estabelecimento e a preservação, em favor da pessoa e dos cidadãos, de condições materiais mínimas de existência (ADPF 45/DF, Rel. Min. CELSO DE MELLO, Informativo/STF $\left.n^{\circ} 345 / 2004\right)$. Cumpre advertir, desse modo, que a cláusula da "reserva do possível" - ressalvada a ocorrência de justo motivo objetivamente aferível - não pode ser invocada, pelo Estado, com a finalidade de exonerar-se, dolosamente, do cumprimento de suas obrigações constitucionais, notadamente quando, dessa conduta governamental negativa, puder resultar nulificação ou, até mesmo, aniquilação de direitos constitucionais impregnados de um sentido de essencial fundamentalidade (ADPF 45 MC/DF, Supremo Tribunal Federal, Relator: Min. Celso de Mello. Julgado em 29 de maio de 2004). (Grifo do autor). 
Imaginemos a seguinte situação hipotética. Suponhamos que um grupo restrito de indivíduos é portador de uma doença fatal, de rápido avanço, todavia curável, cujo tratamento só é feito noutro país. Entretanto, o valor do tratamento é tão estratosférico, com o custo tão substancial, que caso o Estado resolva arcar, por consequência restará frustrado o conjunto de políticas públicas fundamentais em favor de toda uma população pobre residente em seu território. Considere que esse suposto grupo restrito de indivíduos resolveu ajuizar uma ação coletiva que poderá gerar um gasto extremamente elevado no caso de êxito judicial.

Decerto afirmar que os medicamentos que o grupo de indivíduos necessita fazem parte não só do mínimo existencial, aliás, se trata de uma questão de sobrevivência. Como um Juiz enfrentaria essa solução? Ele escolheria salvar o grupo ou colocaria em risco o direito à saúde da população carente inteira do Estado?

Os estudos de Alexy (2007), com o propósito de resolver casos emblemáticos, revelaram os princípios e os valores ocultos contidos nas regras e na jurisprudência. A sua primordial pretensão era dar cientificidade a problemas que surgiam a partir das diferenças estruturais entre princípios. Para isso, defende que os direitos fundamentais possuem caráter de princípios e, nesse particular, eles poderiam eventualmente se colidir, sendo assim necessária uma solução ponderada em favor de um deles.

No intuito de responder possíveis impasses entre princípios, o autor alemão utiliza um critério de ponderação dividido em três fases. Primeiramente, ele utiliza a técnica de adequação. Adequado no sentido de promover o fim desejado, não infringindo outro ou outros princípios presentes no ordenamento jurídico. Segundo, ele utiliza o critério da necessidade. Significa que não há outro princípio menos restritivo com custo menor. Em outras palavras, o meio não será necessário se há um outro mais suave ou menos restritivo no caso concreto. Terceiro, se porventura esses critérios anteriores não resolverem o impasse, deve-se colocar os princípios em colisão numa balança, a fim de precisar qual deles é racionalmente mais importante na situação concreta (ALEXY, 2007).

Portanto, numa situação hipotética como essa, o juiz deveria se valer da ponderação, observando a técnica de Alexy a título de sugestivo.

Disserta Paulo Caliendo:

A chamada reserva do possível pode ser de ordem fática (falta de recursos) ou jurídica (orçamentária). A ausência total de recursos necessários para o atendimento de um direito a prestações impede faticamente o cumprimento da demanda social, pouco restando questionamento. Cabe esclarecer que esta insuficiência de recursos deve ser provada e não apenas alegada, sob pena de responsabilidade do administrador ( CALIENDO, 2013, p.180). 
Diante disso, entendemos que a reserva do possível, desde que objetivamente comprovada pelo Estado, é um elemento fático limitador também do mínimo existencial em situações de extrema excepcionalidade.

Retornando para a situação hipotética de conflitos de direitos levantada neste último capítulo, pergunta-se: a reserva do possível funcionaria ali como um elemento fático limitador do mínimo existencial do suposto grupo acometido por doença gravíssima? Não há dúvida. A reserva do possível aplicada na situação imaginária evitaria que o governo realizasse cortes profundos no sistema público de saúde hipotético. Sem essa proteção (reserva do possível), milhões de pessoas poderiam ser sacrificadas devido ao corte severo de recursos. Na balança da justiça o peso de milhões pessoas é superior que a de um grupo restrito de indivíduos.

Ainda nessa conjuntura, a reserva do possível é garantidora de direitos fundamentais, porque evita toda a frustração de um complexo e trabalhoso planejamento orçamentário, que é finito, escasso, destinado a atender demandas mais urgentes da população. As decisões judiciais não podem, em tese, tornar o planejamento orçamentário ineficaz, planejamento este que beneficia uma população inteira. Afinal, sob o ponto de vista lógico, sacrificar o todo por causa da demanda de certo grupo de pessoas é lesar os direitos fundamentais de toda a coletividade.

No sentindo metafórico, pode existir uma lona grande e de longo alcance que proteja várias frutas dos efeitos solares, mas não são todas. Pode-se até esticar um pouco mais a lona para proteger mais frutas, porém, mesmo assim, sobrarão algumas desprotegidas. O que não se deve fazer é esticar demais a lona a ponto de rasgá-la e deixar todas as frutas desprotegidas.

Portanto, em tese a reserva do possível não pode afastar o mínimo existencial, salvo se há comprovação da falta absoluta de recursos ou quando a demanda atendida de uns acarrete comprovadamente a lesão dos direitos fundamentais de muitos.

\section{CONCLUSÃO}

Em balanço do que foi apresentado neste artigo, podemos transluzir que a judicialização da política no Brasil foi fruto de uma sequência histórica onde o Estado transitou do paradigma liberal para o Estado Social. A Constituição de 1988, por sua vez, acrescentou mais uma transição: o Estado Social passa a ser o Estado Democrático de Direito. Inaugura-se uma nova função para o Estado. Ele se torna o agente transformador da realidade social, pois traça metas, programas e planos no campo das políticas públicas que efetivam os direitos sociais. Inclusive, a Constituição, além de conter todo esse planejamento, fornece os meios para se cumprir todas essas nuances políticas.

Nesse panorama, o Poder Judiciário abandona de vez a antiga visão liberal de que o juiz age como se fosse apenas a "boca da lei". Ocorre o fenômeno 
da politização da justiça, resultando na perda da neutralidade do judiciário em detrimento do avanço das atividades judiciais sobre as relações sociais. No entanto, esse novo modelo vem gerando sérias controvérsias.

Questiona-se a legitimidade da ingerência do Poder Judiciário nas políticas públicas, já que os juízes não são eleitos pelo voto popular. Afirmase que tal ingerência não é democrática, pois não é o povo que escolhe juízes. Em contraste, advoga-se que a legitimidade democrática dos juízes advém da própria constituição, que ademais trouxe a função política para os juízes. De fato, é condição democrática o respeito aos direitos fundamentais sociais. É dever da magistratura garantir esse respeito.

Contudo, mais outra polêmica brota. A tutela judicial dos direitos sociais gera a obrigação do Estado de realizar gastos públicos. A situação se torna mais problemática quando se verifica um cenário de escassez de recursos. O Estado não consegue prover o direito de todos. Alega-se, em suma, a reserva do possível, pois a efetividade dos direitos fundamentais depende de custos.

Parte da doutrina, citada neste trabalho, entende que a reserva do possível não é oponível ao mínimo existencial, pois sem mínimo existencial inexiste democracia. Todavia, o mínimo existencial não é absoluto e a reserva do possível também não deixa de ser uma garantia dos direitos fundamentais de toda uma coletividade. Portanto, concluímos que não se deve esticar demais a lona a ponto de rasga-la e deixar todas os alimentos desprotegidos diante de um dia tão ensolarado.

\section{REFERÊNCIAS}

ALEXY, Robert et al. Teoría de los derechos fundamentales. Centro de Estudios Políticos y Constitucionales, 2007.

AMARAL, Gustavo. Direito, escassez e escolha. Rio de janeiro: Renovar, v. 200, 2001.

ARANGO, Rodolfo. Direitos fundamentais sociais, justiça constitucional e democracia. Os desafios dos direitos sociais. Porto Alegre: Livraria do Advogado, 2005.

BARCELLOS, Ana Paula de. A Eficácia dos Princípios Constitucionais. Dignidade da Pessoa Humana. Rio de Janeiro: Renovar, 2003.

. Neoconstitucionalismo, direitos fundamentais e controle das políticas

públicas. Revista de Direito Administrativo 240, 2005

Constitucionalização das políticas públicas em matéria de direitos fundamentais: o controle político-social e o controle jurídico no espaço democrático. Revista de Direito do Estado, v. 3, n. 17, p. 34, 2006. 
BERCOVICI, Gilberto. Planejamento e políticas públicas: por uma nova compreensão do papel do Estado. In: Políticas públicas: reflexões sobre o conceito jurídico. Maria Paula Dallari Bucci (Org.) São Paulo: Saraiva, 2006

BICKEL, Alexander M. The least dangerous branch: the Supreme Court at the bar of politics. Yale University Press, 1986.

BINENBOJM, Gustavo. A nova jurisdição constitucional brasileira: legitimidade democrática e instrumentos de realização. Rio de Janeiro: Renovar, 2001.

BITENCOURT NETO, Eurico. O direito ao mínimo para uma existência digna. Porto Alegre: Livraria do Advogado, 2010.

BRASIL. Constituição (1988). Constituição da República Federativa do Brasil. Disponível em:< http://www.planalto.gov.br/ccivil_03/constituicao/ constituicaocompilado. htm>. Acesso em: 5 de janeiro de 2018.

BRASIL. Supremo Tribunal Federal. Medida Cautelar em Arguição de Descumprimento de Preceito Fundamental - ADPF MC n. 45. Arguido: Presidente da República. Arguente: PSDB. Relator: Min. Celso de Mello. Distrito Federal, 30 abr. 2004. Disponível em: < http:/ / www.prr4.mpf.gov.br/pesquisaPauloLeivas/arquivos / ADPF45.htm >. Acesso em: 24 de junho de 2018.

BUCCI, Maria Paula Dallari. As políticas públicas e o direito administrativo. Revista trimestral de direito público, v. 13, p. 133 - 144, 1996.

Direito Administrativo e Políticas Públicas. São Paulo: Saraiva, 2002.

CALIENDO, Paulo. Reserva do possível, direitos fundamentais e tributação. TIMM, Luciano Benetti.(org). Direitos fundamentais: orçamento e "reserva do possível, $2^{\circ}$ Ed, 2013.

CANELA JUNIOR, Osvaldo. A efetivação dos direitos fundamentais através do processo coletivo: o âmbito de cognição das políticas públicas pelo Poder Judiciário. 2009. Tese de Doutorado. Universidade de São Paulo.

CANOTILHO, José Joaquim Gomes. Tomemos a sério os direitos econômicos, sociais e culturais. 1988 .

Direito constitucional e teoria da constituição, v. 7, p. 51, 2003.

CITTADINO, G. Poder Judiciário, ativismo judiciário e democracia. Revista Alceu, Rio de Janeiro, v. 5, n. 9, p. 105-113, jul./dez. 2004

COMPARATO, Fábio Konder. Ensaio sobre o juízo de constitucionalidade de políticas públicas. Revista de informação legislativa, v. 35, n. 138, p. 39-48, 1998. 
CORDEIRO, Karine da Silva. Direitos fundamentais sociais, dignidade da pessoa humana e mínimo existencial: o papel do poder judiciário na sua efetivação. 2011. Dissertação de Mestrado. Pontifícia Universidade Católica do Rio Grande do Sul.

COSTA, Flávio Dino de Castro et al. A função realizadora do poder judiciário e as políticas públicas no Brasil. Revista CEJ, v. 9, n. 28, p. 40-53, 2005.

DALLARI, Dalmo de Abreu. Elementos de teoria geral do Estado. São Paulo: Saraiva. 2007.

FONTE, Felipe de Melo. Políticas Públicas e Direitos Fundamentais: elementos de fundamentação do controle jurisdicional de políticas públicas. São Paulo: Saraiva, 2013.

FREIRE JÚNIOR, Américo Bedê. O controle judicial de políticas públicas. São Paulo: Revista dos Tribunais, v. 140, 2005.

GALDINO, Flávio. Introdução à teoria dos custos dos direitos: direitos não nascem em árvores. Rio de Janeiro: Lúmen Júris, 2005.

GRAU, Eros Roberto. O Direito posto e o Direito pressuposto. 8. ed. São Paulo: Malheiros, 2011.

GRIMM, Dieter. Constitutional Adjudication and Democracy. Israel Law Review, v. 33, n. 2, p. 193-215, 1999.

GRINOVER, Ada Pellegrini. Caminhos e descaminhos do controle jurisdicional de políticas públicas no Brasil. 2014.

HÄBERLE, Peter. Die Verfassung des Pluralismus. Königstein: Athenäum, 1980.

HABERMAS, Jürgen; SIEBENEICHLER, Flávio Beno. Direito e democracia: entre facticidade e validade. Rio de Janeiro: Tempo Brasileiro, 2003.

JUNIOR, Tercio Sampaio Ferraz. O Judiciário frente à divisão dos poderes: um princípio em decadência?. Revista Usp, n. 21, p. 12-21, 1994

KRELL, Andreas J. Direitos sociais e controle judicial no Brasil e na Alemanha: os (des) caminhos de um direito constitucional "comparado". SA Fabris Editor, 2002.

LEIVAS, Paulo Gilberto Cogo. Teoria dos direitos fundamentais sociais. Porto Alegre: Livraria do Advogado, p. 129, 2006.

LOPES, José Reinaldo de Lima. Em torno da "reserva do possível". SARLET, Ingo, 2008.

MASSA-ARZABE, Patrícia Helena. Dimensão jurídica das políticas públicas. Políticas públicas: reflexões sobre o conceito jurídico. São Paulo: Saraiva, p. 51-74, 2006. 
LUPION, Ricardo. O direito fundamental à saúde e o princípio da impessoalidade.

Direitos fundamentais: orçamento e "reserva do possível", v. 2, p. 311-324, 2008.

MACHADO, Jónatas Eduardo Mendes. Liberdade de expressão. Dimensões

Constitucionais da Esfera Pública no Sistema Social. 2001. Tese de Doutorado.

MAIA, Antonio Cavalcanti. Direitos humanos e a teoria do discurso do direito e da democracia. Arquivos de direitos humanos. Rio de Janeiro: Renovar, v. 2, p. 5, 2000.

MELLO, Celso de. ADPF 45/9. Ministro Celso de Melo. Disponível em: http:/ /www. stf. jus. br/portal/peticaoInicial/verPeticaoInicial. asp.

MONTESQUIEU. O espírito das leis. Martins Fontes, 2000.

MORAIS, Dalton Santos. Os custos da atividade administrativa e o princípio da eficiência. Revista de Direito Administrativo, v. 237, p. 165-196, 2004.

NASCIMENTO, Rogério Soares do. A ética do discurso como justificação dos direitos fundamentais na obra de Jürgen Habermas. Legitimação dos direitos humanos. Rio de Janeiro, Renovar, p. 451-498, 2002.

PEGORARO, Luis Nunes. O controle da administração pública e a cláusula da "reserva do possível". Revista Juris Síntese, n. 55, 2005.

PEREIRA, Jane Reis Gonçalves. Interpretação constitucional e direitos fundamentais: uma contribuição ao estudo das restrições aos direitos fundamentais na perspectiva da teoria dos princípios. Renovar, 2006.

QUEIROZ, Cristina. Direitos fundamentais sociais: questões interpretativas e limites de justiciabilidade. Interpretação constitucional. São Paulo: Malheiros, p. 165-216, 2005.

SARLET, Ingo Wolfgang; FIGUEIREDO, Mariana Filchtiner. Reserva do possível, mínimo existencial e direito à saúde: algumas aproximações. Direitos Fundamentais e Justiça, Porto Alegre, ano 1, n.1.p. 177 - 178, out -dez. 2007.

A eficácia dos direitos fundamentais. Livraria do Advogado Editora, 2008.

Dignidade da Pessoa Humana e Direitos Fundamentais:: Na Constituição Federal de 1988. Livraria do Advogado Editora, 2018.

SARMENTO, Daniel. Direitos fundamentais e relações privadas. Editora Lumen Juris, 2004.

SCHAFER, Jairo Gilberto. Direitos fundamentais: proteção e restrições. Livr. do Advogado, 2001.

SIERRA, Vânia Morales. A judicialização da política no Brasil e a atuação do assistente social na justiça. Revista Katálysis, v. 14, n. 2, 2011. 
SOUZA NETO, Cláudio Pereira de. Fundamentação e normatividade dos direitos fundamentais: uma reconstrução teórica à luz do princípio democrático. A nova interpretação constitucional: ponderação, direitos fundamentais e relações privadas. Rio de Janeiro: Renovar, 2003.

TORRES, Ricardo Lobo. Os direitos humanos e a tributação: imunidades e isonomia. Renovar, 1995.

O direito ao mínimo existencial. Renovar, 2009.

VIANNA, Luiz Werneck; BURGOS, Marcelo Baumann; SALLES, Paula Martins.

Dezessete anos de judicialização da política. Tempo social, v. 19, n. 2, p. 39-85, 2007.

WANG, Daniel Wei Liang. Escassez de recursos, custos dos direitos e reserva do possível na jurisprudência do STF. Revista Direito GV, v. 4, n. 2, p. 539-568, 2008. 